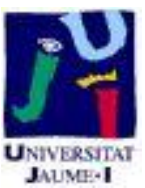

Título artículo / Títol article: Energy saving in ceramic tile kilns: Cooling gas heat recovery

Autores / Autors

Mezquita, Ana ; Boix, Juan ; Monfort Gimeno, Eliseo ; Mallol Gasch, Gustavo

Revista:

Applied Thermal Engineering Vol. 65, no. 1-2, 2014

Versión / Versió:

Cita bibliográfica / Cita

MEZQUITA, Ana, et al. Energy saving in ceramic tile kilns: bibliogràfica (ISO 690): Cooling gas heat recovery. Applied Thermal Engineering, 2014, vol. 65, no 1, p. 102-110.

url Repositori UJI:

http://hdl.handle.net/10234/124003 


\title{
ENERGY SAVING IN CERAMIC TILE KILNS: COOLING GAS HEAT RECOVERY
}

\author{
Ana Mezquita, Juan Boix, Eliseo Monfort, Gustavo Mallol \\ Instituto de Tecnología Cerámica (ITC). Asociación de Investigación de las Industrias Cerámicas \\ (AICE). \\ Universitat Jaume I. Castellón. Spain.
}

\begin{abstract}
A great quantity of thermal energy is consumed in ceramic tile manufacture, mainly in the firing stage. The most widely used facilities are roller kilns, fuelled by natural gas, in which more than $50 \%$ of the energy input is lost through the flue gas and cooling gas exhaust stacks.

This paper presents a calculation methodology, based on certain kiln operating parameters, for quantifying the energy saving obtained in the kiln when part of the cooling gases are recovered in the firing chamber and are not exhausted into the atmosphere. Energy savings up to $17 \%$ have been estimated in the studied case.

Comparison of the theoretical results with the experimental data confirmed the validity of the proposed methodology. The study also evidenced the need to improve combustion process control, owing to the importance of the combustion process in kiln safety and energy efficiency.
\end{abstract}

KEYWORDS: ceramic tile, roller kiln, heat recovery, energy efficiency

\section{HIGHLIGHTS:}

Some energy input (30 - 35\%) in ceramic roller kilns is lost through the cooling gas stack.

Cooling air is directly recovered in the combustion chamber, providing oxygen.

This energy recovery from the cooling gas stack has been quantified.

It has been proven that the proposed methodology to estimate energy savings is valid.

\section{INTRODUCTION}

The ceramic tile manufacturing process consists of various stages, which differ as a function of the product made. The main tile production stages are: the raw materials preparation, the tile forming, drying, glazing and decorating, and firing [1].

When the tile body and glaze are fired together, the manufacturing process is known as single firing. Sometimes, however, the tile body is fired first; the fired body is then decorated and subjected to a second thermal cycle to fire the glaze. This process is called double firing. The most common ceramic tile manufacturing process is the single-firing process, which is schematically illustrated in Figure 1. 


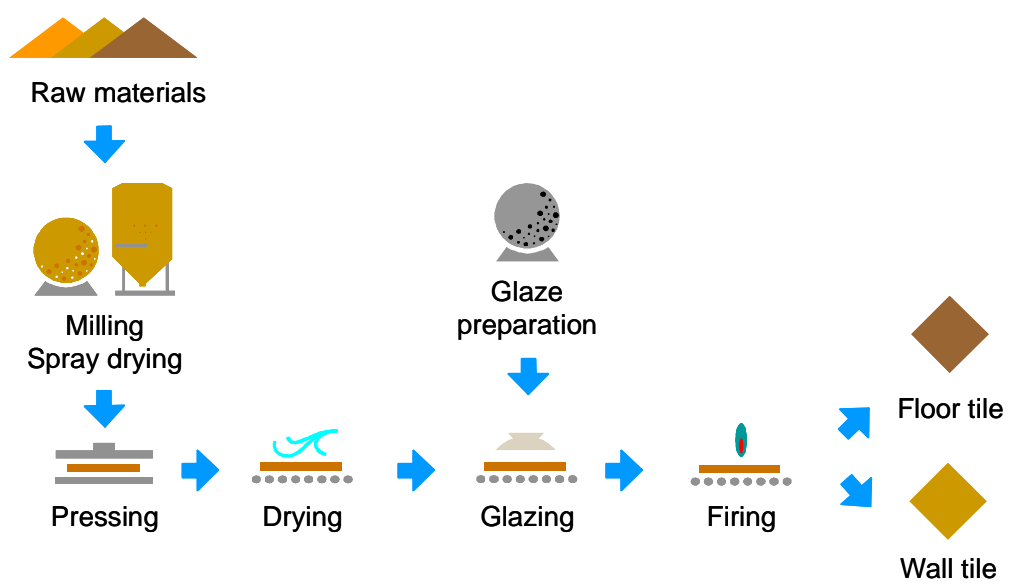

Figure 1. Schematic illustration of the single-fired ceramic tile manufacturing process.

Several ceramic tile manufacturing stages require thermal energy [2]. Thermal energy consumption takes place mainly in three process stages: spray drying of ceramic slurries, drying of the freshly formed tile bodies, and tile firing. Figure 2 shows the average percentage distribution of thermal energy consumption in these three stages. The greatest energy consumption occurs in firing, which accounts for $55 \%$ of all thermal energy used in tile manufacture [3].

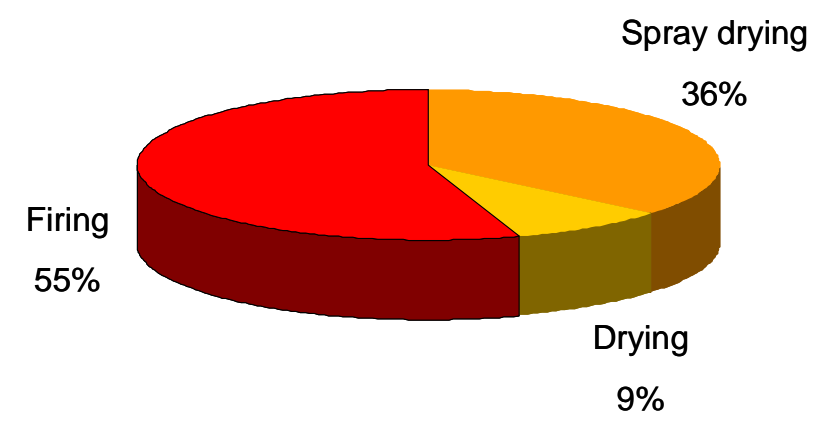

Figure 2. Breakdown of the main thermal energy consumption in ceramic tile manufacture.

Average thermal energy consumption in ceramic tile manufacture is estimated to be $4608 \mathrm{~kJ} / \mathrm{kg}$ fired tile, relative to the lower heating value (LHV) of natural gas. As noted, the firing stage consumes the most thermal energy, with an average value of $2556 \mathrm{~kJ} / \mathrm{kg}$ fired tile.

The energy required in the process is obtained by combustion of natural gas, which is a fossil fuel. Natural gas combustion gives rise to air emissions of carbon dioxide, a greenhouse gas, the emissions of which are internationally subject to control and abatement measures. Ceramic tile manufacture is one of the activities envisaged in the European legislation on greenhouse gas emission allowance trading (see Annex I of Directive 2003/87/EC) [4]. According to this Directive, before 2013 most European ceramic tile companies did not exceed the thresholds set and were therefore not affected by this directive. However, the new Directive 2009/29/EC, in force since 2013 establishes a new legal framework through which most tile companies are becoming part of the emissions trading system [5].

The $\mathrm{CO}_{2}$ emissions produced by natural gas combustion in ceramic tile manufacture are estimated to be about $265 \mathrm{~kg} \mathrm{CO} / \mathrm{t}$ fired tile [6]. These emissions account for about $90 \%$ of all $\mathrm{CO}_{2}$ emissions in the tile manufacturing process, while the emissions from the decomposition, during firing, of the calcium and/or magnesium carbonates present in tile bodies account for about $10 \%$ of all $\mathrm{CO}_{2}$ emissions in the process. 
Thermal energy costs currently make up about $15 \%$ of total ceramic tile manufacturing costs. However, this figure varies, basically owing to changes in fuel prices, which depend on political and market situations beyond the industrial process.

Reducing kiln energy consumption decreases energy costs and $\mathrm{CO}_{2}$ emissions. On the other hand, owing to the EU legislation on emissions trading, $\mathrm{CO}_{2}$ emissions can also entail an economic cost for companies. Consequently, lowering thermal energy consumption decreases manufacturing costs and enhances company competitiveness [7]. Moreover, lower natural gas consumption means that better use is made of natural resources, thus contributing to international policies aimed at reducing fossil fuel consumption [8], following the roadmap to move to a competitive low carbon economy [9].

Most ceramic tiles are fired in continuous roller kilns, in which the tiles are conveyed through the kiln on rollers. Heat is produced by natural gas combustion in the burners. The combustion gases are exhausted from the kiln through a stack located at the kiln entrance [10]. After crossing the peak temperature zone, the tiles are cooled by direct contact with the ambient air that is fed into the kiln. Cooling gases are usually exhausted through the cooling stack, though they are sometimes recovered in other process stages [11], principally in drying, or as combustion air in the burners of the same kiln, as it is done in other industrial processes [12].

Energy balances drawn up on ceramic tile kilns, based on thermodynamic analysis [13], have shown that kiln efficiency is low, because only 5 to $20 \%$ of the energy input is used in firing the tiles (that is, in the chemical reactions involved in material transformations). The rest is lost through the flue gas stacks $(20-25 \%)$ and cooling stacks $(30-35 \%)$, with the fired tiles $(5-10 \%)$, and through the kiln walls and vault $(10-15 \%)$.

The main input and output streams of a ceramic tile kiln and the context on which the energy balance is drawn up are illustrated in Figure 3.

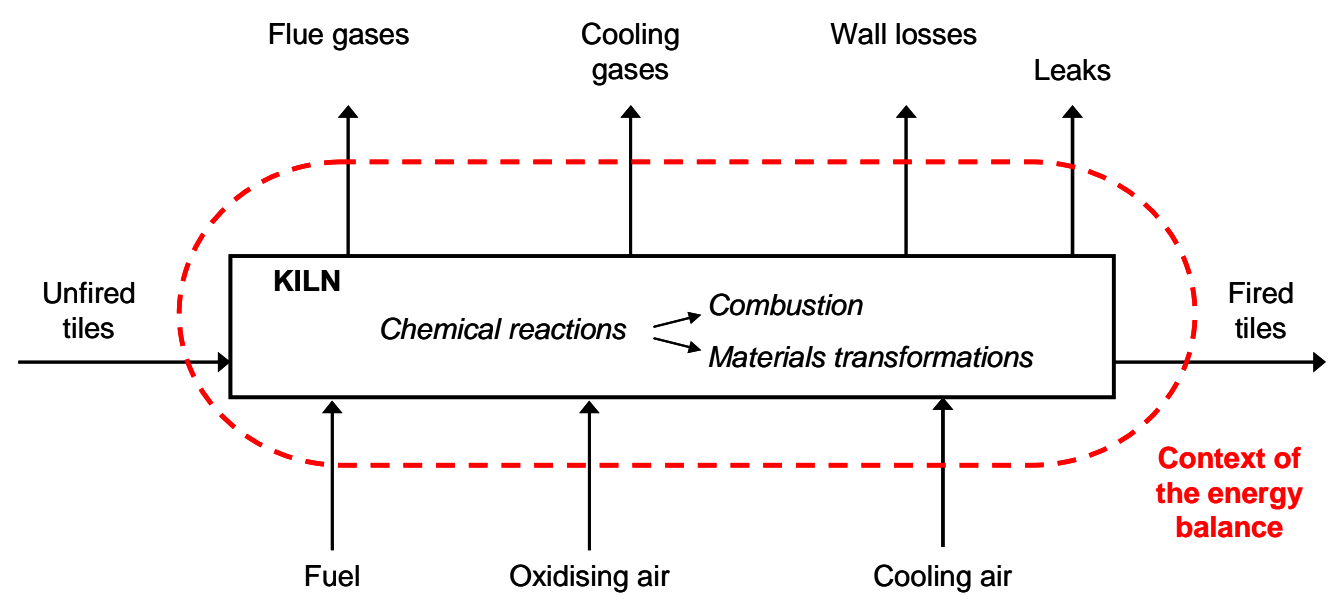

Figure 3. Streams involved in the energy balance of a ceramic tile kiln.

Previous studies have examined the influence of certain firing process variables such as static pressure and oxygen content in the combustion chamber on kiln energy consumption [14]. To date, the energy saving obtained from heat recovery of part of the cooling gases in the ceramic tile kilns has not been evaluated [15]. However, the optimisation of heat recovery have been studied for tunnel kilns [16], and the hot air sent from the cooling zone to the firing zone has been considered in mass and energy balances made in studies developed for tunnel kilns [17].

\section{OBJECTIVE AND SCOPE OF THE STUDY}

This study was undertaken to quantify the energy saving achieved by direct heat recovery of the cooling gases in the combustion chamber.

The procedure developed is applicable to natural gas-fuelled roller kilns for firing ceramic tiles. 


\section{DESCRIPTION OF THE FACILITY}

The studied ceramic tile kiln was a single-deck roller kiln, 90 metres long, made up of 43 modules, each of which was 2.10 metres long. The plane formed by the rollers conveying the tiles divided the kiln into a top and a bottom chamber, in which different firing temperatures could be set. The product being manufactured during the study was porcelain tile.

Heat was produced by natural gas combustion in the kiln burners, into which air and gas were fed through different openings. The combustion products were propelled at great speed (above $100 \mathrm{~m} / \mathrm{s}$ ) through the burner nozzles into the kiln, which facilitated heat transmission by convection towards the ceramic tiles [15].

The burners were arranged in rings. Each ring consisted of a group of burners that were regulated and controlled as a function of the temperature recorded by a kiln control thermocouple. The thermal firing cycle was, thus, controlled by a series of thermocouples that regulated the power input of the different kiln burner rings.

The studied kiln contained 168 burners. These were arranged in 22 rings, of which 2 contained 12 burners, 16 contained 8 burners, and 4 contained 4 burners.

The oxidiser used in the burners was air recovered from the cooling stack and diluted with ambient air to a working temperature of $105 \stackrel{\circ}{\circ}$. The oxidising air was fed into the burner rings through an insulated duct at a constant pressure, regulated by an impeller fan fitted with a frequency inverter. The combustion air flow rate could be regulated manually at every burner with a valve located in the air supply duct to each burner. However, the most common industrial practice is to work with a similar air pressure in all kiln burners.

The flue gases produced by natural gas combustion in the burners were exhausted through the flue gas stack at the kiln entrance. A pressure transducer was fitted in the maximum temperature zone (at about $45 \mathrm{~m}$ from the kiln entrance) to continuously monitor the static pressure in that kiln zone. The flue gas exhaust fan was fitted with a frequency inverter and control system that automatically regulated fan rotation speed to keep the static pressure at the programmed setting.

The flue gas stack contained an ambient air intake to reduce the gas temperature and protect the fan. The first kiln modules were also fitted with air intakes to reduce the gas temperature and, thus, favour gradual heating of the tiles in order to facilitate evaporation of the tile water content. (If water evaporation occurs abruptly, tiles can explode.)

The firing zone was separated from the cooling zone by a firewall. Firewalls are physical barriers that are fitted in the kiln modules to separate different kiln zones in the channel above and the channel below the level of the roller plane. The firewalls in the bottom channel of the studied kiln consisted of refractory bricks, whereas the firewalls in the top channel consisted of rigid insulation boards.

The firewalls served two purposes: on the one hand, to prevent gases from passing from one kiln zone to another (this was the case of the firewalls located at the end of the firing zone and beginning of the cooling zone) and, on the other, to reduce the transverse temperature differences in a given zone by raising gas static pressure in that zone.

The ceramic tiles were cooled in three stages as they travelled through the studied kiln. In the first and last stages, ambient air was directly injected into the kiln to cool the tiles. In the middle stage, between 600 and $500 \stackrel{\circ}{\circ}$, ambient air was circulated through metal tubes in the kiln to provide indirect cooling because the allotropic transformation of quartz takes place at about $573^{\circ} \mathrm{C}$. This transformation produces a change in tile volume. Much gentler cooling is, therefore, required in this temperature range to avoid tile breakage.

The cooling stack exhausted cooling gases from the kiln. Part of these gases was recovered in the burners, for use as combustion air to reduce energy consumption [19], while the rest was exhausted into the atmosphere. The studied kiln is schematically illustrated in Figure 4. 


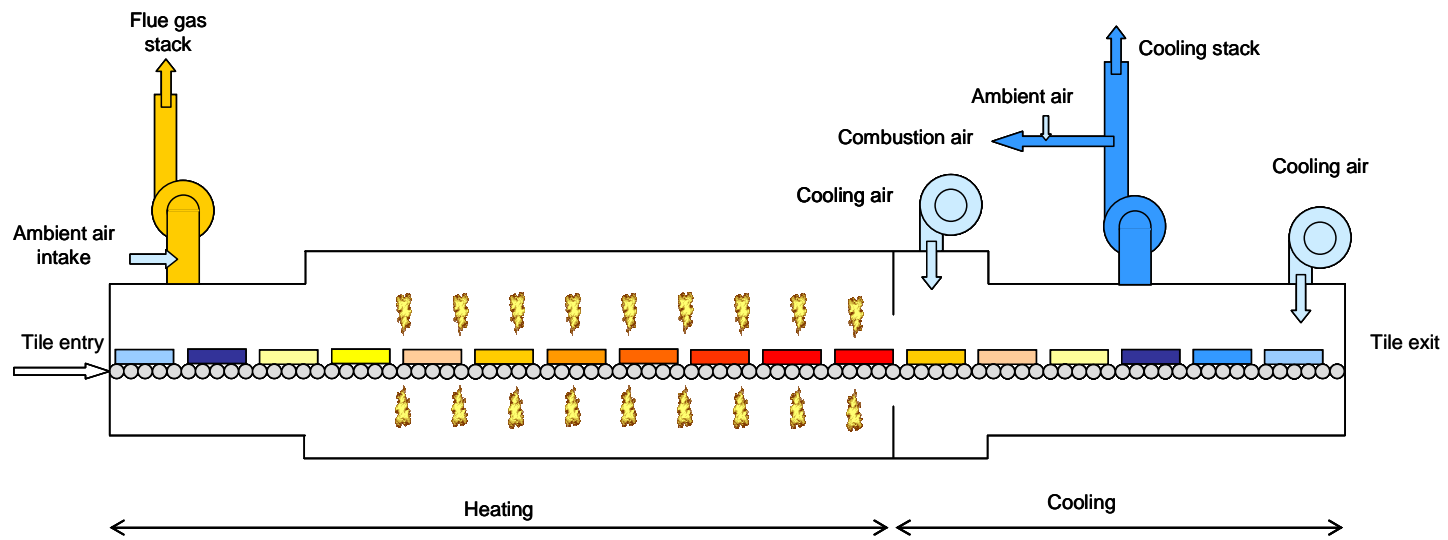

Figure 4 . Scheme of the studied ceramic tile kiln.

\section{EXPERIMENTAL PROCEDURE}

The experimental procedure consisted of several phases. First, the kiln atmosphere was analysed by determining the static pressure profile (which allowed the direction of the gas circulation to be established) and by measuring the real oxygen content in the combustion chamber (in order to maintain product quality and optimise the combustion process) [20]. A detailed study was then performed of the combustion process in the burners to determine the excess air coefficient in the burners. The data obtained were then used to estimate the volume flow of the cooling gases recovered in the combustion chamber.

The procedure used in each determination is described below.

\subsection{Static pressure and oxygen content profiles}

The static pressure and oxygen content in the kiln were determined by introducing a hollow rod of refractory material (alumina) connected, respectively, to a pressure gauge or a gas analyser, through small openings (known as peepholes) in the side walls of the kiln [14]. The uncertainties in the measurements of static pressure and oxygen content are $1 \mathrm{~Pa}$ and $0,2 \%$, respectively.

Static pressure and oxygen content were determined throughout the entire firing cycle at $n$ measurement points, located both above and below the roller plane, to obtain the complete longitudinal profiles in the combustion chamber.

\subsection{Analysis of the combustion system}

The combustion system was analysed by determining the excess air coefficient in the kiln burners. This parameter was calculated from the following expression:

Equation 1

$$
\lambda=\frac{Q_{a r}}{Q_{a m}}=\frac{Q_{C}}{Q_{g} \cdot V_{a m}}
$$

where:

$Q_{a r}$ : real volume flow rate of the air (oxidiser flow rate) fed into the kiln $\left(m_{N}^{3} / s\right){ }^{(*)}$

$Q_{a m}$ : minimum volume flow rate of the air or stoichiometric air flow rate $\left(\mathrm{m}_{\mathrm{N}}^{3} / \mathrm{s}\right)$

${ }^{(*)} 1 \mathrm{~m}_{\mathrm{N}}^{3}=1 \mathrm{~m}^{3}$ air under standard conditions, at $273 \mathrm{~K}$ and $101325 \mathrm{~Pa}$ 
$\mathrm{Q}_{\mathrm{C}}$ : oxidiser volume flow rate $\left(\mathrm{m}_{\mathrm{N}}^{3} / \mathrm{s}\right)$

$\mathrm{Q}_{\mathrm{g}}$ : natural gas volume flow rate $\left(\mathrm{m}_{\mathrm{N}}^{3} / \mathrm{s}\right)$

$\mathrm{V}_{\mathrm{am}}$ : minimum dry air volume $\left(\mathrm{m}_{\mathrm{N}}^{3} / \mathrm{m}_{\mathrm{N}}^{3}\right.$ natural gas $)$

In order to analyse the combustion system, the gas and air volume flow rates were determined in the burners and the excess air coefficient was calculated from these values.

The gas and air volume flow rates were determined from the natural gas and air static pressures in the burners. The uncertainty in these measurements of static pressures are $1 \mathrm{~Pa}$.The relationship between the pressures and the volume flow rates was supplied by the burner manufacturer in the form of equations [21].

\subsection{Estimation of the volume flow rate of the recovered cooling air}

The relationship between the pressures measured in the burners and the gas and air volume flow rates was calculated from the following expressions, which were supplied by the burner manufacturer.

Equation $2 \quad\left(Q_{g}\right)_{j}=-3.33 \cdot 10^{-7} \cdot\left(P_{g}\right)_{j}^{2}+2.77 \cdot 10^{-3} \cdot\left(P_{g}\right)_{j}+5.67 \cdot 10^{-1}$

Equation $3 \quad\left(Q_{C}\right)_{j}=-5.45 \cdot 10^{-6} \cdot\left(P_{C}\right)_{j}^{2}+3.70 \cdot 10^{-2} \cdot\left(P_{C}\right)_{j}+6.75$

Where:

$\left(Q_{g}\right)_{j}$ : natural gas volume flow rate in burner $\mathrm{j}\left(\mathrm{m}_{\mathrm{n}}^{3} / \mathrm{h}\right)$

$\left(P_{g}\right)_{j}$ : natural gas static pressure measured in burner $\mathrm{j}\left(\mathrm{N} / \mathrm{m}^{2}\right)$

$\left(Q_{C}\right)_{j}$ : air volume flow rate in burner $\mathrm{j}\left(\mathrm{m}_{\mathrm{n}}^{3} / \mathrm{h}\right)$

$\left(P_{C}\right)_{j}$ : air static pressure measured in burner $\mathrm{j}\left(\mathrm{N} / \mathrm{m}^{2}\right)$

These expressions are valid for an oxidising air temperature of $105{ }^{\circ} \mathrm{C}$, this being the combustion air temperature in the studied kiln.

The data compiled in the analysis of the kiln combustion system and the oxygen content determined in the different kiln zones enabled the volume flow rate of the cooling gases that passed into the firing zone to be estimated.

This calculation was made by minimising the sum of the differences squared of the oxygen contents measured at each point and the values estimated from natural gas combustion in the burners, modifying the volume flow rate of the cooling gases that entered the firing zone and the volume flow rate of the air fed in through the burners of the first two kiln rings.

In order to estimate the oxygen content in a given kiln zone, it was necessary to establish the oxygen volume flow rate through the burners, as well as the total gas volume flow rate in each zone. This gas volume flow rate depended, in turn, on the cooling gas volume flow rate it was sought to estimate, so that the calculation process was iterative.

The total gas volume flow that circulated through the kiln increased from the firing zone towards the kiln entrance, owing to the progressive incorporation of the combustion gases from the burners, as is schematically illustrated in Figure 5.

The studied kiln was divided into 11 zones $\left(Z_{i}\right.$, with $\left.i=1 \ldots 11\right)$. Each of these zones contained two burner rings, one above and the other below the roller plane. The combustion gas volume flow rate in each zone $\left(Q_{\mathrm{Hi}}\right)$ was assumed to be the result of the sum of the volume flow of the two rings in the zone. 


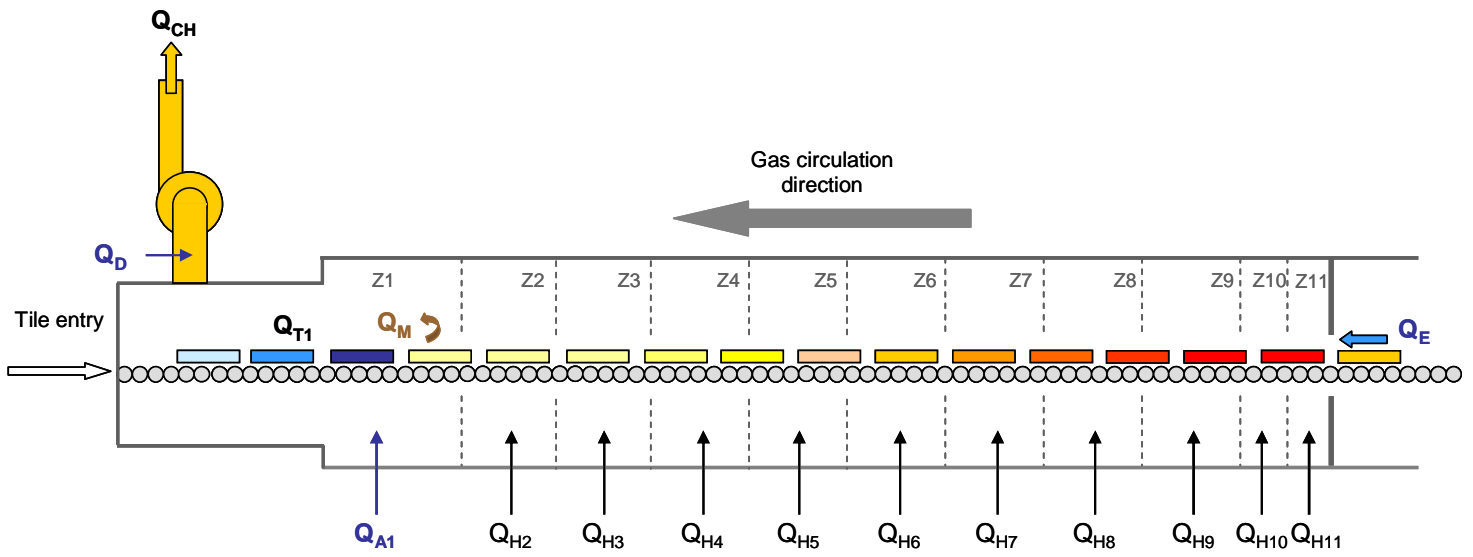

Figure 5. Scheme of the kiln firing zones.

The burners in zone 1 were not ignited, though they fed air into the kiln $\left(Q_{A_{1}}\right)$.

The total gas volume flow that moved from one zone (i) to the next ( $\mathrm{i}-1)\left(\mathrm{Q}_{\mathrm{Ti}}\right)$ was calculated from the following expression:

Equation $4 \quad \mathrm{Q}_{\mathrm{Ti}}=\left(\mathrm{Q}_{\mathrm{M}}+\mathrm{Q}_{\mathrm{Ai}}\right)_{\mathrm{i}=1}+\left(\sum_{\mathrm{i}>1}^{11} \mathrm{Q}_{\mathrm{Hi}}\right)+\mathrm{Q}_{\mathrm{E}}$

where:

$Q_{E}$ : volume flow rate of the gases coming from the cooling zone $\left(\mathrm{m}_{\mathrm{n}}^{3} / \mathrm{s}\right)$

$Q_{H i}$ : volume flow rate of the combustion gases in zone $i\left(\mathrm{~m}_{\mathrm{n}}^{3} / \mathrm{s}\right)$. This volume flow rate was calculated from equation 5 :

Equation $5 \quad Q_{H i}=Q_{g i} \cdot\left(V_{h m}+\left(\lambda_{i}-1\right) \cdot V_{a m}\right)$

where:

$Q_{g i}$ : volume flow rate of the natural gas consumed in the rings in zone $i\left(m_{n}^{3} / h\right)$. This value was calculated from the experimentally determined gas pressures in the burners using equation 2 (see section 4.3).

$V_{h m}$ : minimum flue gas volume $\left(m_{N}^{3} / m_{N}^{3}\right.$ natural gas).

$\lambda_{\mathrm{i}}$ : excess air coefficient in zone i.

In the specific case of zone 1 , the volume flow rate of the water vapour from clay mineral dehydroxylation $\left(Q_{M}\right)$, calculated from kiln tile production and from the losses on ignition of the processed tile composition, as well as the volume flow rate of the air fed in through the burners in zone $1\left(Q_{A 1}\right)$, was added to the total gas volume flow rate $\left(Q_{T 1}\right)$.

The oxygen content in each kiln zone was estimated from equation 6 :

Equation 6 $\quad \chi_{\mathrm{O}_{\mathrm{i}}}=\frac{\mathbf{Q}_{\mathrm{O}_{\mathrm{i}}}}{\mathbf{Q}_{\mathrm{Ti}_{\mathrm{i}}}} \cdot \mathbf{1 0 0}$

where:

$\chi_{\mathrm{O}_{\mathrm{i}}}$ : estimated oxygen volume fraction in zone $\mathrm{i}(\%)$. 
$\mathbf{Q}_{\mathbf{O}_{\mathbf{i}}}$ : oxygen volume flow rate in zone i $\left(\mathrm{m}_{\mathrm{n}}^{3} / \mathrm{h}\right)$. The oxygen volume flow rate was the sum of the oxygen volume flow in the cooling gases, and of the oxygen present in the combustion gases of the burners located in zone $i$ and in the preceding firing zones (in the direction of gas advance). This was calculated from equation 7 :

$$
\text { Equation } 7 \quad \mathrm{Q}_{\mathrm{O}_{\mathrm{i}}}=\chi_{\mathrm{O} 2 \text { air }} \cdot\left(\mathrm{Q}_{\mathrm{Ai}}\right)_{\mathrm{i}=1}+\left(\sum_{\mathrm{i}>1}^{11} \mathrm{Q}_{{\mathrm{O} 2 \mathrm{H}_{\mathrm{i}}}_{\mathrm{i}}}\right)+\chi_{\mathrm{O} 2 \text { air }} \cdot \mathrm{Q}_{\mathrm{E}}
$$

where:

$\mathbf{Q}_{\mathrm{O}_{\mathbf{E}}}$ : oxygen volume flow rate in the cooling gases $\left(\mathrm{m}_{\mathrm{n}}^{3} / \mathrm{h}\right)$

$\mathbf{Q}_{\mathbf{O}^{2} \mathrm{H}_{\mathrm{i}}}$ : oxygen volume flow rate in the combustion gases in zone $\mathrm{i}\left(\mathrm{m}_{\mathrm{n}}^{3} / \mathrm{h}\right)$. This value was calculated from equation 8 , it being known that air has an oxygen content $\left(\chi_{\mathrm{O}_{2} \text { air }}\right)$ of $20.9 \%$.

$$
\text { Equation } 8 \quad \mathrm{Q}_{\mathrm{O}_{2} \mathrm{H}_{\mathrm{i}}}=\mathrm{Q}_{\mathrm{g}_{\mathrm{i}}} \cdot \mathrm{V}_{\mathrm{am}} \cdot\left(\lambda_{\mathrm{i}}-1\right) \cdot \chi_{\mathrm{O}_{\text {air }}}
$$

In order to calculate the oxygen content in zone $1\left(Q_{O 2_{1}}\right)$ it was also necessary to consider the oxygen contributed by the air fed in through the burners.

The above calculation procedure is schematically illustrated in Figure 6.

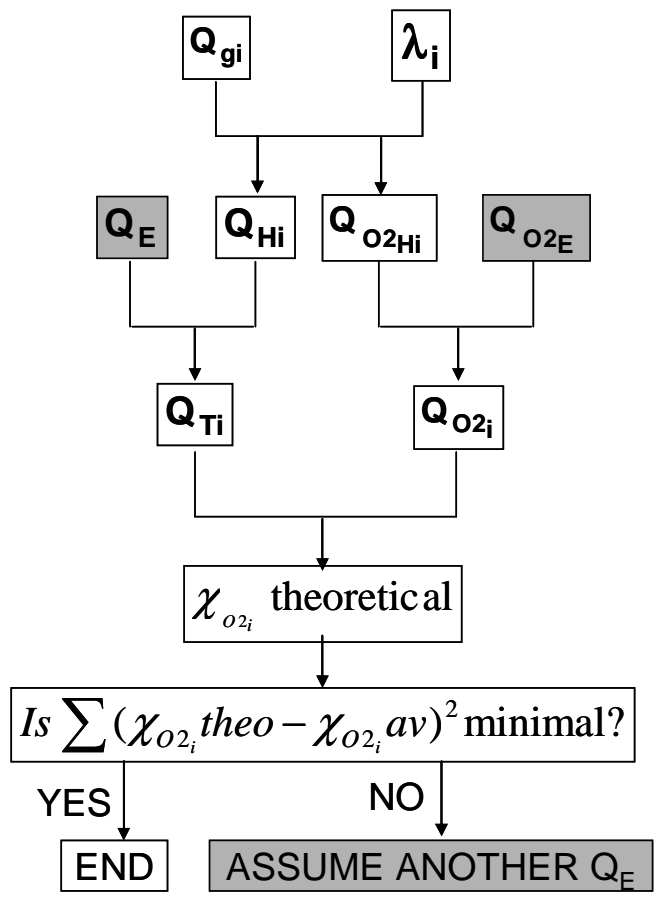

Figure 6 .Calculation procedure.

\section{RESULTS OBTAINED}

\subsection{Static pressure and oxygen content profiles}

The experimentally determined static pressure and oxygen content, as well as the programmed temperature, are plotted versus kiln length in Figure 7 . The short vertical lines indicate the positions of 
the firewalls in the kiln firing zone; the long vertical line indicates the firewall separating the peak temperature zone from the cooling zone.

The results obtained show that the static pressure in the kiln progressively increased from the start of the thermal cycle up to the cooling zone. The lowest pressure was observed at the kiln entrance, owing to fan suction in the flue gas stack.

The static pressure was less than 0 throughout the entire heating stage and almost up to firing end. Beyond this point, the pressure became positive, reaching its maximum value in the cooling zone.

The pressure profile displayed two clearly different stretches. Pressure increased in a practically linear form, with a slope of $0.22 \mathrm{~Pa} / \mathrm{m}$, from the kiln entrance to $47 \mathrm{~m}$ into the kiln. At this point the slope changed, and the pressure then increased more rapidly $(0.76 \mathrm{~Pa} / \mathrm{m})$ up to the beginning of the cooling zone.

The change in slope was probably due to the presence of the firewalls in the kiln at $50.4 \mathrm{~m}$ and $52.5 \mathrm{~m}$ from the entrance.

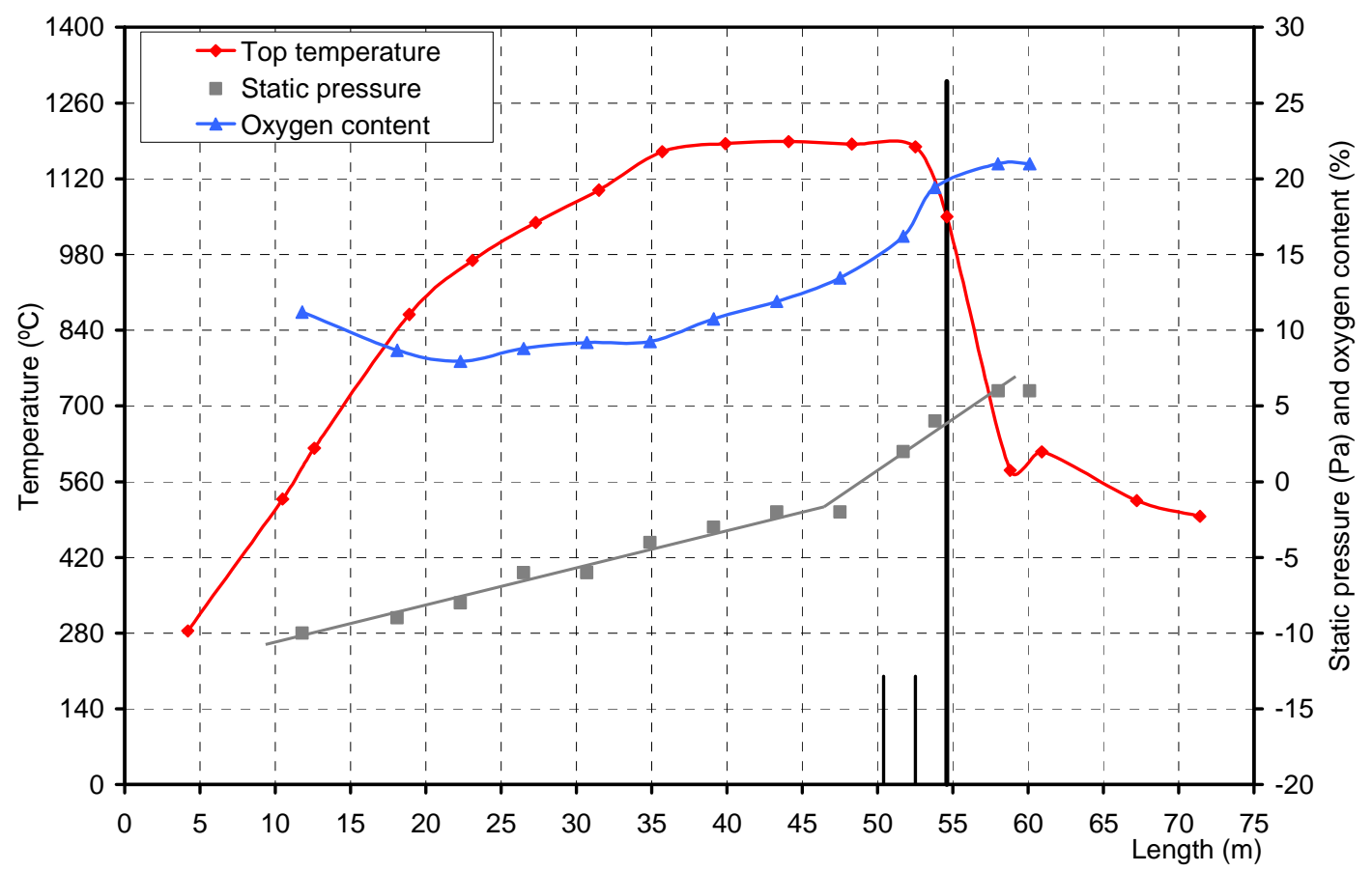

Figure 7. Static pressure and oxygen content profiles in the kiln.

The maximum static pressure in the kiln was located in the first cooling zone. This indicates that part of the cooling gases passed into the firing zone and circulated countercurrent to the tiles before being exhausted through the flue gas stack at the kiln entrance.

The movement of gases from the cooling zone into the firing zone facilitates cooling gas heat recovery in the kiln, while simultaneously supplying the combustion chamber with oxygen.

The plot of the oxygen content in the kiln shows that the oxygen content in the combustion chamber decreased from the kiln entrance to a distance of $22 \mathrm{~m}$ into the kiln, where it minimised (8\%). The temperature setting there was $950 \stackrel{\circ}{\circ}$. Beyond this point, the oxygen content rose to a maximum value of $20.9 \%$ in the fast cooling zone. This result is consistent with the measured static pressures: it confirms that no gases travelled from the firing zone into the cooling zone.

Oxygen is thus present in such tile kilns because natural gas combustion takes place with excess air, and cooling gases (with an oxygen content of $20.9 \%$ ) pass from the cooling zone into the firing and heating zones.

It may be noted that ceramic tiles need to be fired in an oxidising atmosphere because this assures complete combustion of the fuel and burnout of the organic matter contained in the tiles. It may further be noted that certain glaze and decorative applications are sensitive to the oxygen content in the 
atmosphere, so that an inappropriate oxygen content in the combustion chamber can also affect the colour of the glazed surface finish.

\subsection{Combustion system}

In order to analyse the kiln combustion system, the air and gas volume flow rates were determined at one burner in each burner ring from the air and gas pressures measured in that burner.

Since ceramic tile kilns are usually not equipped with systems for continuous measurement of the fuel and oxidiser volume flow rates in each burner (or groups of burners), the air and natural gas flow rates were therefore determined from the static pressures measured in the given burners themselves, using information supplied by the burner manufacturer.

The pressures measured in the burners located in the top chamber of the kiln are detailed in Table 1. Those measured in the burners in the bottom chamber are shown in Table 2.

Table 1. Operating conditions of the burner rings in the kiln top chamber.

\begin{tabular}{|c|c|c|c|c|c|c|}
\hline $\begin{array}{c}\text { Combustion } \\
\text { zone }\end{array}$ & $\begin{array}{l}\text { Zone } \\
\text { midpoint } \\
(\mathrm{m})\end{array}$ & $P_{g}\left(N / m^{2}\right)$ & $P_{C}\left(N / m^{2}\right)$ & $Q_{g}\left(m_{n}^{3} / h\right)$ & $Q_{c}\left(m_{n}^{3} / h\right)$ & $\lambda$ \\
\hline $\mathrm{Z1}$ & 14.5 & 0 & 305 & 0 & 224.4 & --- \\
\hline $\mathrm{Z2}$ & 20.8 & 320 & 310 & 11.3 & 141.51 & 1.26 \\
\hline Z3 & 25.0 & 850 & 410 & 21.4 & 167.97 & 0.79 \\
\hline Z4 & 29.2 & 650 & 380 & 17.8 & 160.12 & 0.91 \\
\hline Z5 & 33.4 & 400 & 370 & 13.0 & 157.49 & 1.23 \\
\hline Z6 & 37.6 & 950 & 440 & 23.1 & 175.73 & 0.77 \\
\hline $\mathrm{Z7}$ & 41.8 & 340 & 380 & 11.8 & 160.12 & 1.38 \\
\hline Z8 & 46.0 & 650 & 390 & 17.8 & 162.75 & 0.92 \\
\hline Z9 & 50.2 & 500 & 360 & 14.9 & 154.85 & 1.05 \\
\hline $\mathrm{Z10}$ & 52.3 & 850 & 440 & 10.7 & 87.87 & 0.83 \\
\hline Z11 & 54.4 & 950 & 450 & 11.6 & 89.15 & 0.78 \\
\hline
\end{tabular}


Table 2. Operating conditions of the burner rings in the kiln bottom chamber.

\begin{tabular}{|c|c|c|c|c|c|c|}
\hline $\begin{array}{c}\text { Combustion } \\
\text { zone }\end{array}$ & $\begin{array}{c}\text { Zone } \\
\text { midpoint (m) }\end{array}$ & $P_{g}\left(N / m^{2}\right)$ & $P_{C}\left(N / m^{2}\right)$ & $Q_{g}\left(m_{n}^{3} / h\right)$ & $Q_{c}\left(m_{n}^{3} / h\right)$ & $\lambda$ \\
\hline $\mathrm{Z1}$ & 13.9 & 0 & 340 & 0 & 210.3 & --- \\
\hline Z2 & 20.2 & 1250 & 400 & 28.0 & 165.36 & 0.60 \\
\hline Z3 & 24.4 & 370 & 370 & 12.4 & 157.49 & 1.29 \\
\hline Z4 & 28.6 & 600 & 350 & 16.9 & 152.20 & 0.91 \\
\hline Z5 & 32.8 & 250 & 300 & 9.9 & 138.82 & 1.42 \\
\hline Z6 & 37.0 & 600 & 360 & 16.9 & 154.85 & 0.93 \\
\hline $\mathrm{Z7}$ & 41.2 & 500 & 360 & 14.9 & 154.85 & 1.05 \\
\hline Z8 & 45.4 & 500 & 340 & 14.9 & 149.54 & 1.01 \\
\hline Z9 & 49.6 & 360 & 360 & 12.2 & 154.85 & 1.29 \\
\hline Z10 & 51.7 & 1000 & 440 & 12.0 & 87.87 & 0.74 \\
\hline Z11 & 53.8 & 1100 & 360 & 12.8 & 77.42 & 0.61 \\
\hline
\end{tabular}

Combustion air pressure was constant in the general kiln duct, and the air volume flow rate was manually regulated at each burner. Gas pressure was constant in the burners of a ring. This was automatically regulated to maintain the programmed temperature cycle and, thus, meet the thermal needs of each kiln zone.

The burner rings in the first kiln top and bottom chamber were not ignited. The measured gas pressure was therefore zero in the burner rings in zone 1. However, there was pressure in the combustion air inlet duct to the burner, because air is typically fed into the kiln chamber through these burners in order to keep the temperature from rising too sharply in this zone, as this might cause defects in the tiles.

Tables 1 and 2 show that the air pressure varied much less than the gas pressure in both the top and bottom chambers. Thus while the oxidiser pressure ranged from 305 to $450 \mathrm{~N} / \mathrm{m}^{2}$, natural gas pressure ranged from 250 to $1300 \mathrm{~N} / \mathrm{m}^{2}$ in the burner rings. This was probably because the same type of burner was used for zones in which different heating powers were required to obtain the desired temperature curve.

The total air and gas volume flow rates in each kiln ring were calculated using the experimentally determined natural gas and air pressure data and applying equations 2 and 3 . The excess air coefficient $(\lambda)$ in each combustion chamber zone was then calculated from equation 1 . The values obtained are shown in Tables 1 and 2 . These values have been plotted, together with the real temperature in the top chamber, as a function of kiln length in Figure 8. 


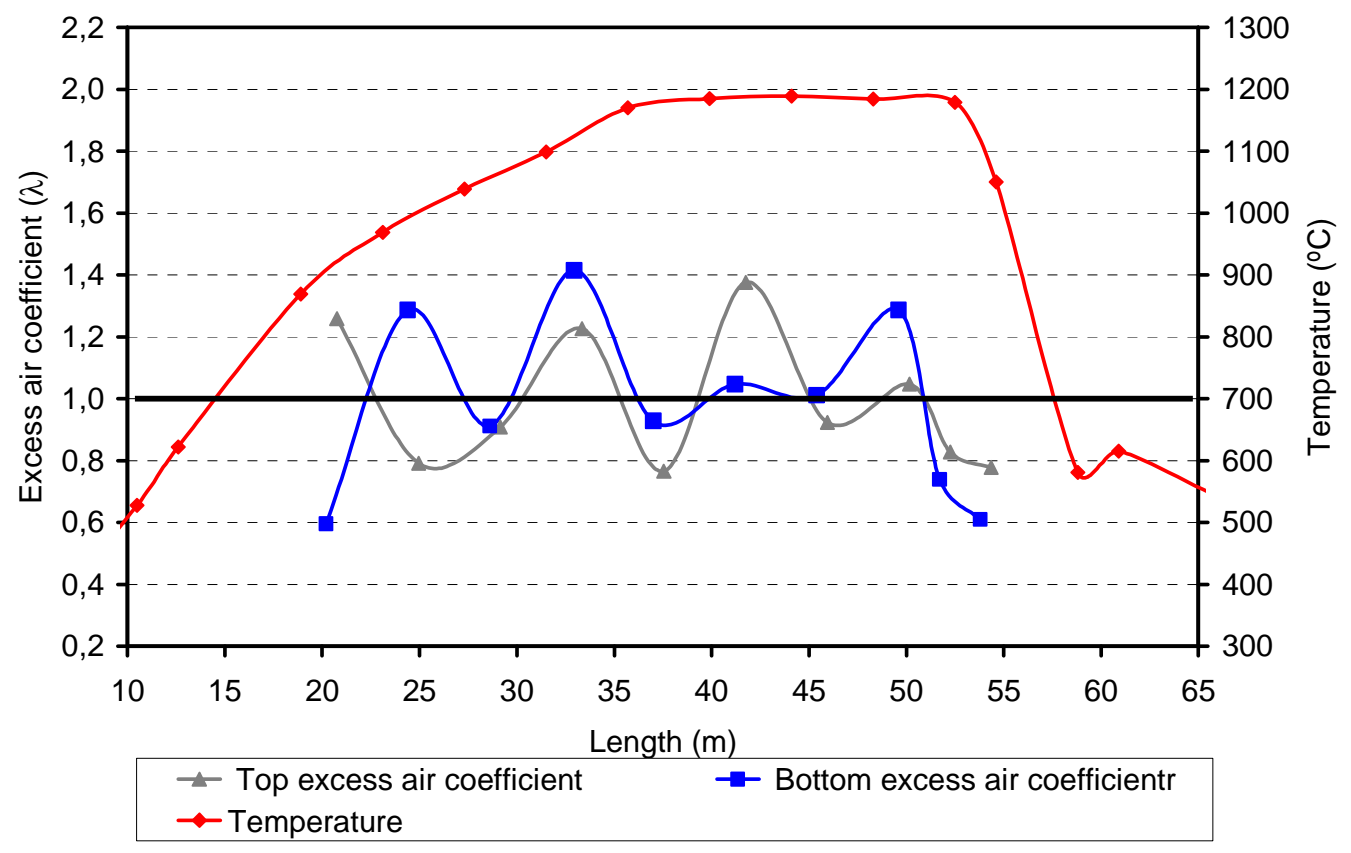

Figure 8. Temperature and excess air coefficient in the kiln.

The results indicate that the burners in the kiln were not uniformly regulated throughout the firing cycle. Nor did the values measured in the kiln top chamber clearly parallel those measured in the bottom chamber, evidenced by the respective lines that crossed each other on various occasions.

The average excess air coefficient, calculated from the gas and oxidiser volume flows measured in the burners (average excess air coefficient in the burners, excluding zone 1), and the value calculated from the oxygen content in the kiln (average excess air coefficient in the kiln) are shown in Table 3.

The average excess air coefficient in the kiln was calculated from the oxygen content of the gases that were exhausted from the kiln, measured in zone Z1.

Table 3. Average excess air coefficient.

\begin{tabular}{|c|c|c|}
\hline Zone & $\begin{array}{c}\text { Average excess air } \\
\text { coefficient in the } \\
\text { burners }\end{array}$ & $\begin{array}{c}\text { Average excess air } \\
\text { coefficient in the kiln }\end{array}$ \\
\hline Top chamber & 0.96 & -- \\
\hline Bottom chamber & 0.93 & -- \\
\hline Entire kiln & 0.95 & 2.11 \\
\hline
\end{tabular}

The average excess air coefficient in the burners, obtained from the air and gas pressures in the burners, was slightly less than one (0.95), indicating that part of the natural gas entered the kiln combustion chamber without being burned.

An excess air coefficient of less than unity was obtained in 11 of the 20 burner rings that were running in the kiln. This situation was dangerous, because it meant that part of the natural gas supplied to the burners was not burned in a controlled way at the burners, but was burned inside the kiln.

The spontaneous combustion temperature of mixtures of air and natural gas lies in the range 650-750 ${ }^{\circ} \mathrm{C}[6]$. In the case at issue, the natural gas was unlikely to leave the kiln without being burned because the temperature in the zones with a shortage of air was always above $900 \stackrel{\circ}{\circ}$. For the sake of safety, however, it is not advisable to have an excess air coefficient below 1 in any group of burners.

In the nine other burner rings running in the kiln, the excess air coefficient was larger than 1, indicating that more air was fed into the combustion process than was stoichiometrically needed to burn the 
natural gas. The volume flow rate of the excess air fed into the kiln was $215 \mathrm{~m}_{\mathrm{n}}^{3} / \mathrm{h}$. Since this excess air volume flow needed to be heated from the input temperature $\left(105^{\circ} \mathrm{C}\right)$ to the temperature programmed in each kiln zone, this entailed an extra natural gas consumption of $25 \mathrm{~m}_{\mathrm{n}}^{3} / \mathrm{h}$, corresponding to about $8.2 \%$ of the total kiln natural gas consumption.

At present, standard ceramic tile kilns are not equipped with systems for measuring and controlling the excess air coefficient in the burners, so that the optimisation of this parameter should be performed manually following the procedure described previously. So, given the importance of this parameter for kiln safety and energy consumption, the obtained results indicate that it would be useful to install control systems of the excess air input into ceramic tile kilns to avoid burner rings in the kiln operating with an excess air below 1 .

General analysis of the results showed that oxygen was present in the combustion chamber. However, the study indicated that this oxygen did not come entirely from the burners because, as noted previously, gases with a composition corresponding to that of air (i.e. containing $20.9 \%$ oxygen) circulated from the cooling zone into the firing zone.

These gases supplied the combustion zone with the oxygen needed to burn the natural gas completely and to oxidise the organic matter contained in the tiles, as well as to appropriately develop the aesthetic characteristics of the tiles being processed, such as through-body colour and colour of the glaze finish.

Indeed, the last four burner rings in the firing zone exhibited an average excess air coefficient of 0.74 . The oxygen needed to burn the unburned natural gas that entered the kiln combustion chamber was thus provided by the cooling gases.

This fact was also evidenced in the calculation of the average excess air coefficient in the kiln (see Table 3). The resulting value (2.11) was much higher than the average excess air coefficient in the burners due to the extra oxygen provided by the gases that came from the cooling zone.

The natural gas feed determined in each group of burners enabled the power input into each kiln zone to be calculated. The results obtained, expressed as a percentage, are shown in Figure 9, together with the cumulative power and the programmed kiln temperature curve.

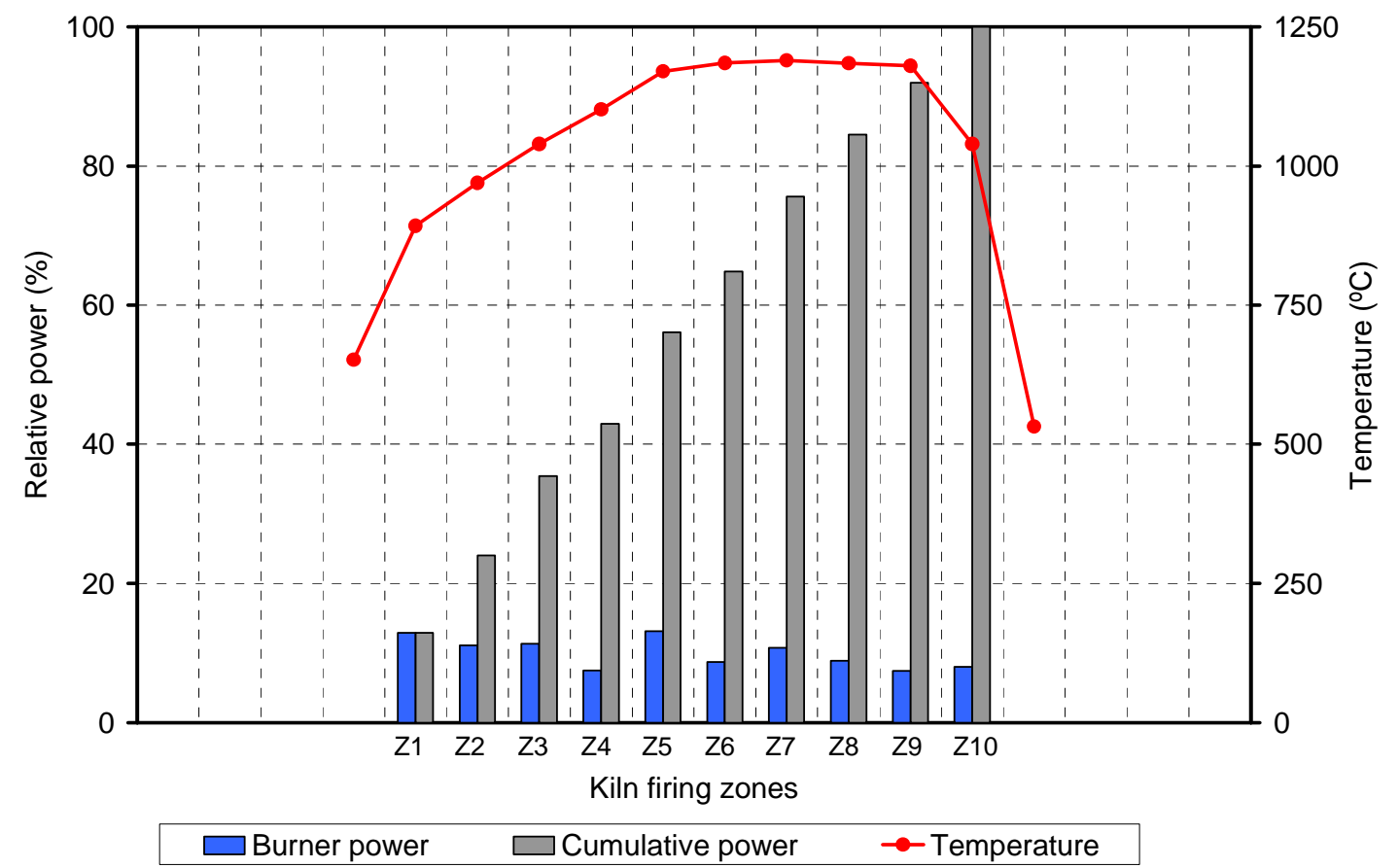

Figure 9. Power supplied by the burners during the firing cycle. 
In the first three firing zones, the burners contributed a great quantity of thermal energy to the kiln. These burners had a high natural gas consumption because they needed to raise the temperature of the tile feed into the kiln.

The burner ring in zone 5 supplied the largest quantity of thermal energy. As a result, owing to the gases that circulated countercurrent to the tiles, fostering heat recovery from the gases, the preceding ring (zone 4) needed to supply less power.

The last two rings in the firing zone needed to maintain the tile peak firing temperature. Their energy contribution was smaller than that of the first kiln rings.

The cumulative plots of the power supplied by the burner rings show that, up to the start of the peak temperature stage (Z5), burner power input was $56 \%$. That is, $56 \%$ of the thermal energy fed into the firing process was used in heating the tiles. The remaining $44 \%$ was used in holding the peak firing temperature.

\subsection{Estimation of the volume flow rate of the recovered cooling air}

The procedure described in section 4.3 was applied to estimate the volume flow rate of the cooling gases, which yielded a value of $1920 \mathrm{~m}_{\mathrm{n}}^{3} / \mathrm{h}$. Using this value, the estimated oxygen content in each kiln zone was fitted to the experimental data (Figure 10).

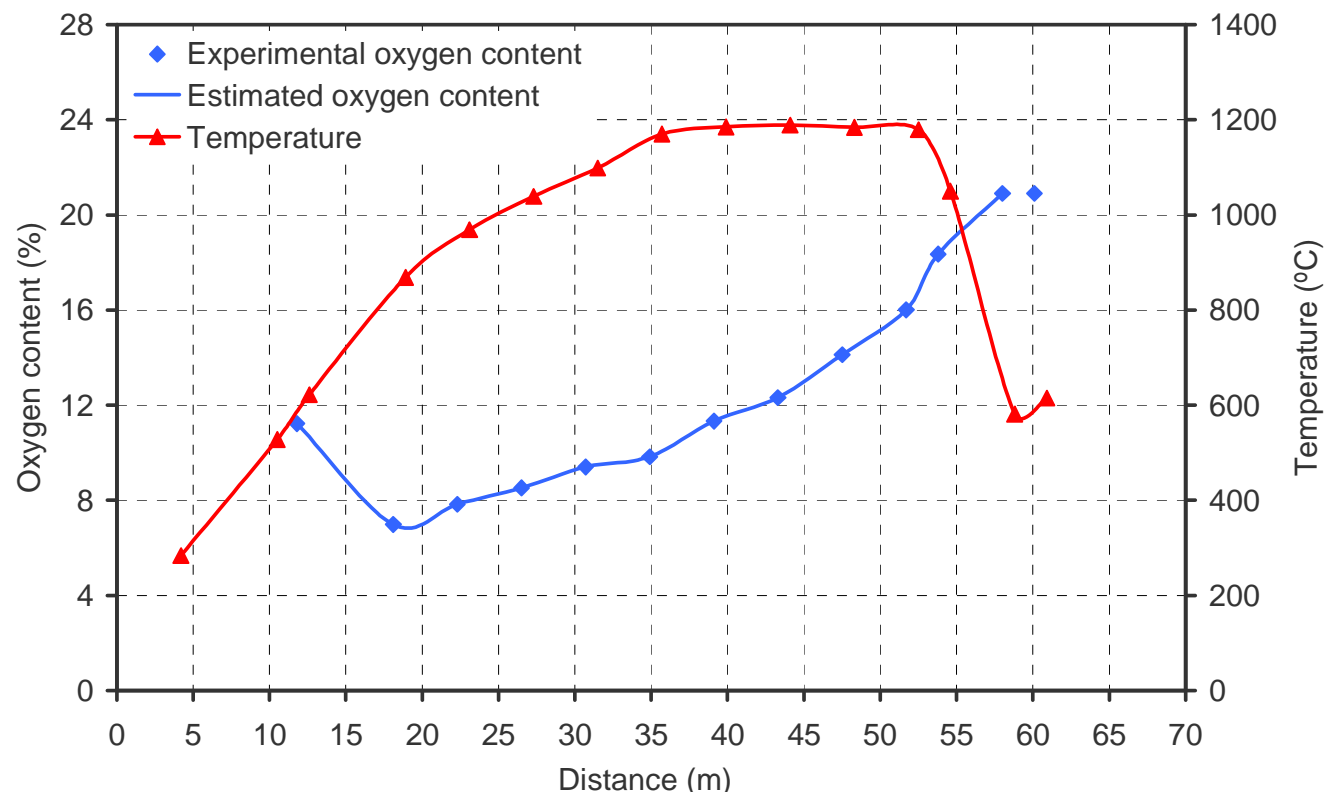

Figure 10. Simulation of the oxygen content in the kiln.

The calculations made allowed certain gas volume flow rates that were not easy to determine experimentally in the kiln, such as the average oxygen volume flow rate $\left(Q_{\mathrm{OxH1}}\right)$ and the total gas volume flow rate at the kiln entrance $\left(\mathrm{Q}_{\mathrm{T} 1}\right)$, to be estimated.

The $Q_{T 1}$ gas stream is customarily diluted with ambient air $\left(Q_{D}\right)$ to reduce the gas stream temperature and avoid damaging the combustion gas extraction fan. Once the flue gas volume flow rate $\left(\mathrm{Q}_{\mathrm{CH}}\right)$ had been experimentally determined, a joint mass and oxygen balance could be drawn up on the flue gas stack in order to estimate the oxygen content of the flue gases exhausted into the atmosphere.

In the studied case, the experimentally determined gas volume flow rate in the flue gas stack $\left(Q_{C H}\right)$ was $22900 \mathrm{~m}_{\mathrm{n}}^{3} / \mathrm{h}$. Application of the mass and oxygen balances yielded the estimated volume flow rate of the dilution ambient air $\left(Q_{D}\right)$ and the estimated oxygen content in the stack gases. The results obtained are shown in Table 4, together with the experimentally determined oxygen content in the stack. 
Table 4. Estimated dilution air volume flow rate and estimated and experimentally determined oxygen content in the flue gas stack.

\begin{tabular}{|c|c|}
\hline Parameter & Value \\
\hline $\begin{array}{c}\text { Estimated dilution air volume flow } \\
\text { rate }\left(\mathrm{Q}_{\mathrm{D}}\right)\end{array}$ & $16180 \mathrm{~m}_{\mathrm{n}}^{3} / \mathrm{h}$ \\
\hline $\begin{array}{c}\text { Estimated oxygen content in the } \\
\text { stack }\end{array}$ & $17.5 \%$ \\
\hline $\begin{array}{c}\text { Experimentally determined oxygen } \\
\text { content in the stack }\end{array}$ & $17.4 \%$ \\
\hline
\end{tabular}

The results show a difference of $0.1 \%$ between the experimentally determined and the estimated values, which confirms the validity of the procedure applied for calculating the volume flow rate of the gases from the cooling zone, the total volume flow rate of the gases from the kiln, the volume flow rate of the dilution ambient air in the flue gas stack, and the oxygen content in the flue gas stack.

The thermal energy contained in the gases that pass from the cooling zone into the firing zone allows energy to be saved, because the kiln burners are not required to supply this energy. In the studied ceramic tile kiln, the temperature of the cooling gases that entered the firing zone was experimentally measured, given an average value around $1000^{\circ} \mathrm{C}$, involving an energy contribution of $685 \mathrm{~kW}$. Since kiln energy consumption was $3276 \mathrm{~kW}$, without this movement of the cooling gases, energy consumption would therefore have been $3961 \mathrm{~kW}$. The maximum potential energy savings provided by the cooling gas heat recovery could be $17,3 \%$, in this kiln.

This energy saving action does not require any special investment, as occurs in other cases [18]. It can be implemented just by adjusting the static pressure in the combustion chamber of the kiln, so as to reach the desired situation, which is to move some cooling gases towards the firing zone. In the studied case, an energy saving of $685 \mathrm{~kW}$, would involve an annual cost saving slightly higher than $190 \mathrm{k} €$ (considering an energy cost of 0,035 €/kWh and 8064 annual working hours).

\section{CONCLUSIONS}

The following conclusions may be drawn from the study:

- The determination of the static pressure and oxygen content profiles in the studied ceramic tile kiln confirmed that gases circulated from the fast cooling zone into the combustion chamber.

o Kiln combustion was analysed by determining the air and gas volume flow rates in the kiln burners. The excess air in each burner ring was determined, which revealed that the excess air varied highly throughout the firing cycle. In the studied case, the average excess air coefficient in the kiln burners was less than one, so the oxygen present in the kiln combustion chamber should come from gases moving from the cooling zone into the firing zone.

- The determination of the air and gas volume flow rates in each burner ring and of the oxygen content in the kiln chamber enabled the gas volume flow rate from the cooling to the firing zone to be estimated. This gas volume flow was estimated to be $1920 \mathrm{~m}_{\mathrm{n}}^{3} / \mathrm{h}$ in the studied kiln, and the average temperature of these gases was considered to be $1000{ }^{\circ} \mathrm{C}$. Cooling gas heat recovery was, therefore, assumed to provide an energy saving of $17.3 \%$ in the kiln.

- The calculation procedure developed also allowed the oxygen content in the combustion gases exhausted through the kiln stack to be estimated. Good agreement was obtained between the theoretically estimated and the experimentally determined values, confirming the validity of the methodology used.

- The excess air coefficient is a parameter that is currently not determined in standard ceramic tile kilns and is consequently not taken into account in kiln management. Given the importance of this parameter for kiln safety and energy consumption, it would be useful to install control systems of the excess air input into ceramic tile kilns in order to monitor the combustion process and help save energy. 


\section{REFERENCES}

[1] M.D. Bovea, E. Díaz-Albo, A. Gallardo, F.J. Colomer, J. Serrano. Environmental performance of ceramic tiles: Improvement proposals. Materials \& Design, 31 (2010), 35-41.

[2] J. Peng, Y. Zhao, L. Jiao, W. Zheng, L. Zeng. $\mathrm{CO}_{2}$ emission calculation and reduction options in ceramic tile manufacture - The Foshan Case. Energy Procedia, 16 (2012), 467 - 476.

[3] E. Monfort, A. Mezquita, R. Granel, E. Vaquer, A. Escrig, A. Miralles, V. Zaera. Analysis of energy consumption and carbon dioxide emissions in ceramic tile manufacture. Bol. Soc. Esp. Ceram. Vidr., 49 (2010), 303-310.

[4] Directive 2003/87/EC of the European Parliament and of the Council of 13 October 2003 establishing a scheme for greenhouse gas emission allowance trading within the Community and amending Council Directive 96/61/EC.

[5] Directive 2009/29/EC of the European Parliament and of the Council of 23 April 2009 amending Directive 2003/87/EC so as to improve and extend the greenhouse gas emission allowance trading scheme of the Community.

[6] A. Mezquita, E. Monfort, V. Zaera. Ceramic tiles manufacturing and emission trading scheme: reduction of $\mathrm{CO}_{2}$ emissions, European benchmarking. Bol. Soc. Esp. Ceram. Vidr., 48(2009), 211-222.

[7] E.A. Abdelaziz, R. Saidur, S. Mekhilef. A review on energy saving strategies in industrial sector. Renew. Sust. Energ. Rev., 15 (2011), 150-168.

[8] M. Hasanuzzaman, N.A. Rahim, M. Hosenuzzaman, R. Saidur, I.M. Mahbubul, M.M. Rashid. Energy savings in the combustion based process heating in industrial sector. Renew. Sust. Energ. Rev., 16 (2012), 4527-4536.

[9] $\operatorname{COM}(2011) 112$. Communication from the commission to the european parliament, the council, the european economic and social committee and the committee of the regions. A Roadmap for moving to a competitive low carbon economy in 2050. Brussels, March 2011.

[10] I. Celades, R. Moliner-Salvador, T. Ros-Dosda, E. Monfort, V. Zaera. Environmental development of the Spanish ceramic tile manufacturing sector over the period 1992-2007. Bol. Soc. Esp. Ceram. Vidr., 51 (2012), 111-118.

[11]F. Cassani. Recovering energy-from kilns, dryers spray driers and mills. Cfi/Ber. DKG, 87(5) (2010), E35-E39.

[12] V. Karamarković, M. Marašević, R. Karamarković, M. Karamarković. Recuperator for waste heat recovery from rotary kilns. Appl. Therm. Eng., 54 (2013), 470-480.

[13]M. Bending, F. Maréchal, D. Favrat. Defining "waste heat" for industrial processes. Appl. Therm. Eng., 61 (2013), 134-142.

[14] J.E. Enrique, A. Blasco, E. Monfort, G. Mallol. Improving energy efficiency in single deck kilns by optimization of the process variables. Cfi/Ber. DKG, 72(5) (1995), 255-260.

[15] C. Agrafiotis, T. Tsoutsos. Energy saving technologies in the European ceramic sector: a systematic review. Appl. Therm. Eng., 21 (2001), 1231-1249.

[16] K. Sinem, K. Küküçada, E. Mançuhan. Model-based optimization of heat recovery in the cooling zone of a tunnel kiln. Appl. Therm. Eng., 28 (2008), 633-641.

[17]E. Mançuhan, K. Küküçada. Optimization of fuel and air use in a tunnel kiln to produce coal admixed bricks. Appl. Therm. Eng., 26 (2006), 1556-1563.

[18] A. Mezquita, E. Monfort, E. Vaquer, S. Ferrer, M.A. Arnal, J. Toledo, M.A. Cuesta. Energy optimisation in ceramic tile manufacture by using thermal oil. Bol. Soc. Esp. Ceram. Vidr., 51 (2012), 183-190. 
[19] M. Shinoda, R. Maihara, N. Kobayashi, N. Arai, S.W. Churchill. The characteristics of a heatrecirculating ceramic burner. Chem. Eng. J., 71 (1998), 207-212.

[20] M. Kaden. Controlling the residual oxygen content of kiln gases. ZI Int., 58 (8) (2005), 26-32.

[21]E. Monfort, G. Mallol, A. Mezquita, R. Granel, E. Vaquer. Study of combustion in industrial ceramic tile manufacturing kilns. In Qualicer'10 XI World Congress on Ceramic Tile Quality. www.qualicer.org/recopilatorio/?idioma=en (consulted: 2013-10-17) 